\title{
Do countries with higher GDP spend more on disabilities? New evidence in OECD countries
}

\author{
Behzad Karami Matin ${ }^{1}$, Ali Kazemi Karyani ${ }^{1}$, Satar Rezaei ${ }^{1}$, Moslem Soofi ${ }^{1}$, Shahin Soltani*1 \\ Received: 25 Dec 2018 \\ Published: 16 Nov 2019 \\ Conflicts of Interest: None declared \\ Funding: Kermanshah University of Medical Sciences
}

\section{*This work has been published under CC BY-NC-SA 1.0 license. \\ Copyright $\odot$ Iran University of Medical Sciences}

Cite this article as: Karami Matin B, Kazemi Karyani A, Rezaei S, Soofi M, Soltani Sh. Do countries with higher GDP spend more on disabilities? New evidence in OECD countries. Med J Islam Repub Iran. 2019 (16 Nov);33:122. https://doi.org/10.47176/mjiri.33.122

Disability not only encounters people with disabilities with physical, intellectual, and sensory limitations but also it imposes remarkable costs on families and governments to provide the needed supports (1-4). According to the World report on disability, $15 \%$ of the world population are living with a kind of disability. Of these, the results of the world health survey indicate that $2.2 \%$ (110 million people) experience remarkable difficulties in functioning (5).

The Organization for Economic Co-operation and Development (OECD) compromises 36 members (28 European countries, 4 American countries, 2 Asian countries, and 2 Australia/Oceania countries) with different socio-economic levels. In 2015, OECD countries spent $8.8 \%$ of their GDP on healthcare, that is around $0.7 \%$ higher compared to 2000 (6). The findings indicate that healthcare spending has outpaced economic growth over the past decades due to rapid advances in medical technologies, assistive devices, population aging, and raising awareness.

To date, various studies have been done to estimate disability costs in different countries. For example, in Australia, the total economic costs of Intellectual disabilities (ID) were estimated to be around $\$ 14,720$ billion annually (7). Ghatneker et al. in 2004, estimated the direct cost of stroke around \$56,024 in Sweden (8). In Germany, total costs for a 4th year following stroke were almost 3 billion Euros.

GDP is a determinant factor in predicting healthcare

Corresponding author: Dr Shahin Soltani, sh-soltani@alumnus.tums.ac.ir

1. Research Center for Environmental Determinants of Health, Health Institute, Kermanshah University of Medical Sciences, Kermanshah, Iran spending in countries. But the pressure on public budgets to devote more funding to healthcare systems has been an outstanding policy concern in OECD countries over the past three decades (9). Thus, some countries like Sweden adopted cost-containment strategies associated with structural changes to control the accelerated growth in healthcare spending so that they started to reducing the size of health settings and the decreasing the number of healthcare professionals in 2000 (10). Since different factors may contribute to Governments' health spending, this study aimed to investigate the factors that can predict public spending on disabilities in OECD countries

The study was a secondary analysis of existing data. In this study, we used the OECD health database to analyze the relationship between GDP and public spending on disabilities. The latest OECD Data from 2013 to 2015 were applied in this research. Regarding the OECD database, we used five indicators of Public Spending on Incapacity (PSI) as the outcome variable, GDP (US dollars/capita), health spending (US dollars/capita), public social spending (US dollars/capita), Gross direct insurance premiums (US dollars/capita), and Disability prevalence (age $>15$ ). To investigate the situation of countries at the same time, we used the available data from 2013 to 2015 as well.

Two Linear regression models performed to estimate the effects of explanatory variables on public spending on in-

$\uparrow$ What is "already known" in this topic:

- The countries with higher GDP tend to spend more on health services.

$\rightarrow$ What this article adds:

- The factors like GDP per capita are stronger predictors than the total GDP.

- Pre-paid schemes like social insurances can decrease the direct governments' expenditure on disabilities and health conditions. - Public social spending can predict the amount of public spending on disabilities. 
capacity (\% of GDP) (PSI). The first model was an unadjusted model to determine the unadjusted relationship between dependent and independent variables. The second model was performed to investigate the adjusted effect of dependent variables. As there was multicollinearity among explanatory variables, Log-Log regression models were performed. Therefore, the coefficient of variables interpreted as elasticity.

In this study, we analyzed data for 36 OECD countries. The mean of PSI as a percentage of GDP, for 32 OECD countries was $2.21 \%$ (SD: \pm 1 ). Turkey had devoted the lowest GDP on incapacity with $0.33 \%$, and Denmark with $4.73 \%$ had allocated the highest percentage of GDP on incapacity. Also, the mean of health spending per capita was USD2, 848.204 (SD: $\pm 1,626.66)$ that Mexico with USD541.21 had the lowest and the US with USD7, 778.12 had the highest health spending per capita among OECD countries (Table 1). Additionally, we compared the mean of PSI between the different countries Using ANOVA. According to Table 2, there were significant differences between the means of PSI in four independent groups $(p \leq 0.017)$. Also, the results of Pearson correlation indicated that there was a positive association between GDP per capita and PSI among the study countries (Coefficient: 0.361, $\mathrm{p} \leq 0.042$ ). In Figure 1, the situation of PSI against the independent variables has been shown.

In model 1, the variables of GDP, public social spending, and gross direct insurance premiums predict the outcome variable significantly. According to this model, 10 percent increase in GDP (per capita), public social spending, gross direct insurance premiums and health spending would increase PSI by $7.65 \%, 7.37 \%, 1.89 \%$, and $4.99 \%$ respectively. However, disability prevalence had no significant correlation with PSI. In model 2 that estimated the adjusted coefficients, there was a significant association between two variables of gross direct insurance premiums and public social spending with PSI (Table 3).

The means comparison by ANOVA showed that the countries with higher GDP per capita dedicate more funds on disabilities. Accordingly, the countries such as Luxembourg, Denmark, Sweden, Norway, Netherland, Island and the United States that belonged to the higher income groups (based on GDP per capita), significantly, had allocated more funds for sicknesses, disabilities, and injuries than the

\begin{tabular}{lcc} 
Table 1. Descriptive statistics for OECD countries (2015) & & Mean (SD) \\
\hline Variables & Frequency & $2.21(1)$ \\
\hline Public spending on incapacity (\% of GDP) & 32 & $41050.5(16706.87)$ \\
GDP (per capita) & 36 & $8146.12(3704.87)$ \\
Public social spending (per capita) & 32 & $2848.204(1626.66)$ \\
Health spending (per capita) & 36 & $3331.51(6278.9)$ \\
Gross direct insurance premiums (per capita) & 36 & $26.32(7.14)$ \\
Disability prevalence for +15 & 30 & \\
\hline
\end{tabular}

Table 2. The mean comparison of PSI (\% of GDP) between OECD countries by GDP (per capita)

\begin{tabular}{lcccc}
\hline GDP (per capita) & Frequency & Mean (SD) & Std. Error & p \\
\hline$(17,000-26,999)$ & 4 & $1.2(0.78)$ & 0.39 & \\
$(27,000-36,999)$ & 9 & $1.91(0.57)$ & 0.19 & \\
$(37,000-46,999)$ & 8 & $2.17(1.00)$ & 0.35 & 0.017 \\
$(\geq 47,000)$ & 11 & $2.85(1.01)$ & 0.3 & \\
Total & 32 & $2.21(1.00)$ & 0.17 & \\
\hline
\end{tabular}

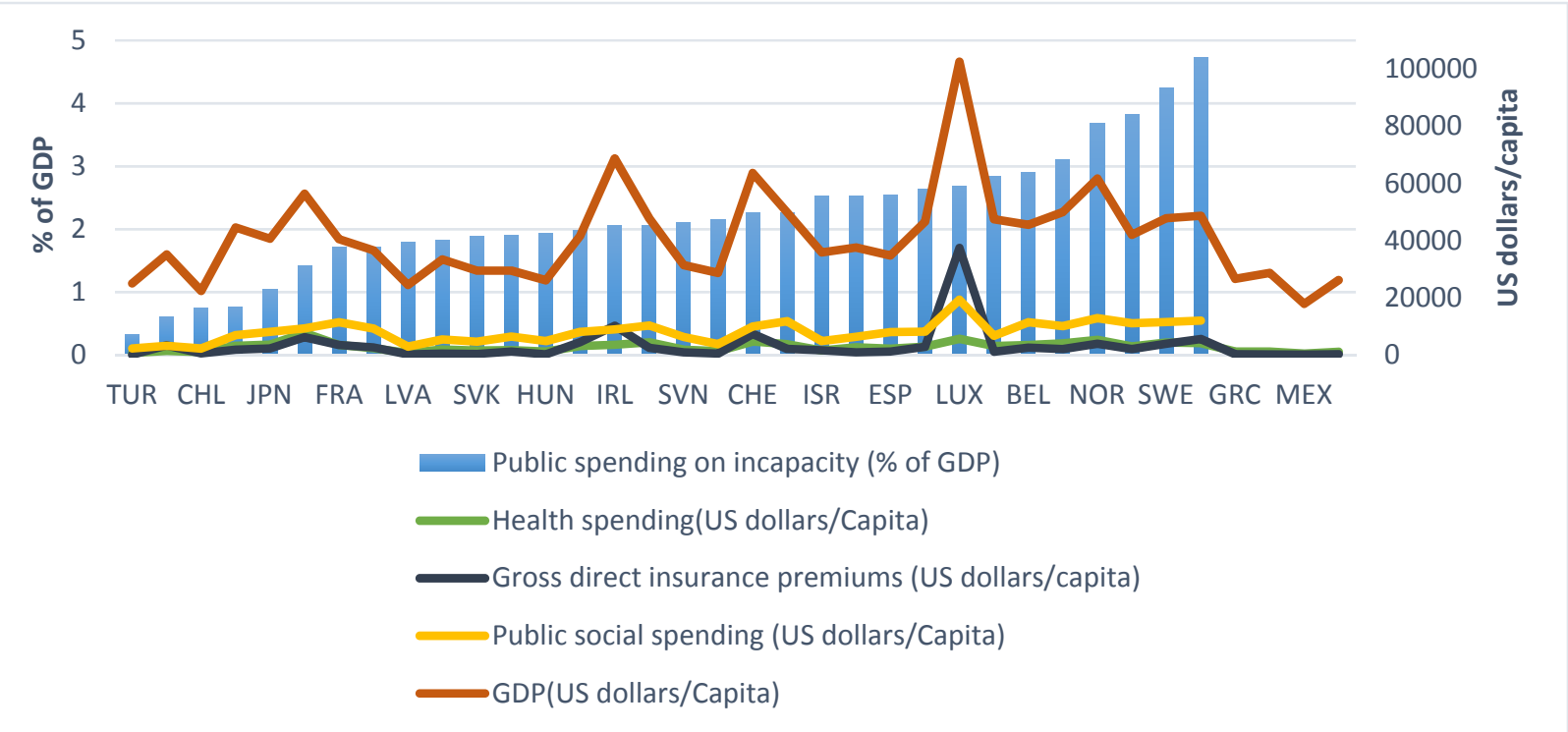

Fig. 1. The association between PSI and the independent variables in OECD countries (2015) 
Table 3. Linear regression analysis for the effect of independent variables on public spending on incapacity

\begin{tabular}{|c|c|c|c|c|c|c|}
\hline \multirow[t]{2}{*}{ Model } & \multicolumn{3}{|c|}{ Unadjusted coefficients } & \multicolumn{3}{|c|}{ Adjusted Coefficients } \\
\hline & Beta & Std.Error & $\mathrm{p}$ & Beta & Std.Error & $\mathrm{p}$ \\
\hline GDP (per capita) & 0.765 & 0.282 & 0.011 & 0.596 & 0.589 & 0.323 \\
\hline Public social spending (per capita) & 0.737 & 0.151 & 0.000 & 0.006 & 0.341 & 0.028 \\
\hline Health spending (per capita) & 0.499 & 0.154 & 0.004 & 0.254 & 0.346 & 0.47 \\
\hline Gross direct insurance premiums (per capita) & 0.189 & 0.084 & 0.032 & -0.29 & 0.141 & 0.052 \\
\hline Disability prevalence $($ for +15$)$ & 0.341 & 0.274 & 0.225 & 0.258 & 0.25 & 0.305 \\
\hline
\end{tabular}

other countries. These results indicate that public spending on disabilities such as disability cash benefits, paid sick, special allowances, and pensions are likely related to the economic situation. However, studies show that health expenditure can affect and predict countries' income. For example, the findings of Halıcı-Tülüce et al. indicated that public health expenditure influences economic growth positively because a healthy labor force can have more productivity than their counterparts with poorer health (11). This result can support the hypothesis that increasing investments in the health sector can be accompanied by the welfare of the population in a distinct period.

The analysis of unadjusted linear regression showed that GDP per capita, public social spending per capita, health spending per capita, and gross direct insurance premiums per capita could predict PSI significantly. In comparison to the previous literature, it could be concluded that health spending can have a direct relationship with public spending on disabilities so that Chan's et al. study shows that activity limitations cause a significant rise in health costs for people with disability (PWD) (12). Also, the findings of Polder et al. in the Netherland indicated that people with intellectual disability and mental disorders use more healthcare than other people with and without disabilities. Accordingly, mental disorders had the highest share of the cost for the Dutch healthcare system in 2002 (13). In addition to disability severity, Factors like aging and life expectancy can increase healthcare costs for PWD and governments. In contrast, it must be noted that disability prevalence could not predict PSI in both unadjusted and adjusted models significantly. This result probably shows that the difference in disability prevalence between the countries is not considerable and significant. In other words, this result probably is due to low data desperation that means variability in the prevalence data is low.

Furthermore, gross direct insurance premiums per capita and public social spending per capita had a significant relationship with PSI in both models. The adjusted model indicated that the countries that their population pays more premiums for insurance programs allocate less budget on illnesses and disabilities. It can be concluded that health insurances as a financing mechanism can reduce governments' expenditure on health conditions. Even, many studies represent that pre-paid schemes like social health insurances can facilitate and accelerate achieving universal health coverage (UHC) in both developing and developed countries. Additionally, public finance through citizen's financial contributions not only provide financial protection but also it can expand a pool of finance to fund the healthcare (14). In contrast, the endogenous growth theories predict that effective public social spending can contribute to the economic growth of countries so that the countries with higher public social spending may have higher GDP than those with lower public social spending.

Also, public social spending per capita could predict PSI in both unadjusted and adjusted models significantly. As expected, public social spending like cash benefits, provision of services and goods and tax breaks that target people with disabilities, elderlies, patients, unemployed and young persons have a significant effect on PSI (15). As a result, public social spending can reflect a dimension of governments' tendency and commitment to PWD and other vulnerable groups.

This study investigated the determinants of PSI in OECD countries. However, this study faced some limitations. First, we only considered the macro variables. The microdata can provide more information about the determinants of PSI for households. The future study can focus on household data to provide more details about the cost drivers of incapacity at the micro-level. However, our findings can inform policymakers about the situation of OECD countries in PSI and provide new evidence about the relationship between PSI and included variables. Second, we used the last data on disability prevalence for European countries in 2012. These data just belonged to the age group of 15 years and above, and we had to consider a similar age group (15 years and above) for other OECD countries. Third, Given that the last data on PSI in 2015 was applied in the present study, we had to consider a similar time point for other data. Also, we just investigated data for 36 OECD countries that had led to low data dispersion for some included variables.

In conclusion, our findings indicated that gross direct insurance premiums per capita and public social spending were two determinant factors to estimate PSI in OECD countries. In brief, higher gross direct insurance premiums can lead to a decrease in direct public expenditure on disabilities and health conditions. On the contrary, countries with higher public social spending are more likely to have higher PSI in comparison to those with lower social spending. Also, our results represented the countries with higher GDP per capita likely devote more funding to incapacities than other countries with lower GDP.

\section{Acknowledgments}

The study was funded by Kermanshah University of Medical Sciences.

\section{Conflict of Interests}

The authors declare that they have no competing interests. 


\section{References}

1. Control CfD, Prevention. Economic costs associated with mental retardation, cerebral palsy, hearing loss, and vision impairment: United States, 2003. 2004.

2. Kruse M, Michelsen SI, Flachs EM, BrØNnum-Hansen H, Madsen M, Uldall P. Lifetime costs of cerebral palsy. Dev Med Child Neurol 2009;51(8):622-8.

3. Tonmukayakul U, Shih STF, Bourke-Taylor H, Imms C, Reddihough D, Cox L, et al. Systematic review of the economic impact of cerebral palsy. Res Dev Disabil. 2018;80:93-101.

4. Soltani S. Hidden cost of disability: What policy makers usually forget. J Res Med Sci. 2018;23:15-.

5. World Health Organization. World Bank (2011) World report on disability. Malta: World Health Organization. 2012.

6. Lorenzoni L, Belloni A, Sassi F. Health-care expenditure and health policy in the USA versus other high-spending OECD countries. The Lancet. 2014;384(9937):83-92.

7. Doran CM, Einfeld SL, Madden RH, Otim M, Horstead SK, Ellis LA, et al. How much does intellectual disability really cost? First estimates for Australia. J Intellect Dev Disabil. 2012;37(1):42-9.

8. Ghatnekar O, Persson U, Glader EL, Terént A. Cost of stroke in Sweden: An incidence estimate. Int J Technol Assess Health Care. 2004;20(3):375-80.

9. Huber M, Orosz E. Health Expenditure Trends in OECD Countries, 1990-2001. Health Care Financ Rev. 2003;25(1):1-22.

10. Ros CC, Groenewegen PP, Delnoij DM. All rights reserved, or can we just copy? Cost sharing arrangements and characteristics of health care systems. Health policy. 2000;52(1):1-13.

11. Halici-Tuluce NS, Dogan I, Dumrul C. Is income relevant for health expenditure and economic growth nexus? Int J Health Econ Manag. 2016;16(1):23-49.

12. Chan L, Beaver S, Maclehose RF, Jha A, Maciejewski M, Doctor JN. Disability and health care costs in the Medicare population. Arch Phys Med Rehabil. 2002;83(9):1196-201.

13. Polder JJ, Meerding WJ, Bonneux L, van der Maas PJ. Healthcare costs of intellectual disability in the Netherlands: a cost-of-illness perspective. J Intellect Disabil Res. 2002;46(Pt 2):168-78.

14. Glassman A, Giedion U, Sakuma Y, Smith PC. Defining a Health Benefits Package: What Are the Necessary Processes? Health Syst Reform. 2016;2(1):39-50.

15. OECD. Social spending (indicator) 2018 [Available from: https:// data.oecd.org/socialexp/social-spending.htm. 